\title{
Marco Fidel Suárez, Clásico de América
}

$\mathbf{L}^{\mathrm{A}}$ Librería Voluntad, casa de amplio respaldo económico, y verdadero taller de la cultura nacional, está publicando la tercera edición de Los sueños de Luciano Pulgar. Han aparecido ya tres volúmeñes de esta nueva serie. 1 Esto prueba que el público sabe distinguir entre el infortunio político de un hombre, y los méritos excelsos de su inteligencia. Porque en Suárez se busca, principalmente, al escritor. Los incidentes de su carrera administrativa están más que juzgados, y la buena o mala calidad de su gobierno es cosa que pertenece al criterio de los políticos profesionales. Siguen debatiéndose algunos aspectos de su carácter, y algunos detalles de su vida, pero aun esto tiene cada vez menos eco y resonancia. Ya poco nos interesa la venta de unos sueldos, $y$ aun parece que esto mismo se ha vuelto en su favor, pues disponiendo del tesoro público, prefirió enajenar sus honorarios para saldar deudas particulares. En todo caso, dentro de algunos años, cuando acabe de serenarse la atmósfera política en torno de su-memoria, tal circunstancia se habrá olvidado completamente; si mucho, se leerá como leemos hoy a los historiadores de Julio César, cuando nos hablan de las abrumadoras deudas que pesaban sobre el conquis-

1 Ultimamente han aparecido los tomos IV, $\mathrm{V}$ y VI (3a. ed.) de Los sueños de Luciano Pulgar. La Librería Voluntad, de Bogotá. merece de vetas aplausos muy sinceros y efusivos por la publicación ordenada de Los sueños de Luciano Pulgar, obra sin par en las letras colombianas contemporáneas, por la tetsura y la limpidez del estilo, y por la riqueza ideológica de su contenido, que colocan a su autor, el infortunado ex presidente de Colombia, don Marco Fidel Suárez, entre los grandes hablistas castellanos de todos los tiempos. (Nota de la Editorial.) 
tador de las Galias. ¿Qué sombra arroja esto sobre el estilo en que están escritos los Comentarios? Ninguna. Es un detalle humano que antes bien pone de manifiesto la condición flaca y voluptuosa del gran conquistador, acercándolo a los hombres de carne y hueso. Tampoco desdice de su valor militar ni de su elegancia mundana el hecho de que lo pinten combatiendo a pie, como cualquier soldado y siempre en las primeras filas. Al señor Suárez se le hicieron cargos enormes y minúsculas ofensas, como la de decir y afirmar la gente que solia tomar un tren para dirigirse a cierto sitio de la Sabana, con el fin de enterrar el dinero ganado en fantásticas especulaciones. Yo escuché la especie muchas veces, y.solía comparar semejante adefesio con la vida austera y pobre que el señor Suárez hacía. Eramos vecinos, y solía yo detenerme a conversar con él algunas veces. Por cierto que siempre llevaba en brazos a su nieto, hoy estudiante universitario, y solia colocarse al pie de un esbelto papayo que había en el patio de su casa, en la Calle Quince, árbol que se divisaba desde la calle y que le daba a ese patio un fresco ambiente santafereño, poco compatible con el ruidoso tranvía que pasaba frente a la casa. Solía encontrarlo también a su salida de la iglesia de La Capuchina, muy a las seis de la manana, cuando acababa de comulgar y en circunstancias en que los exámenes me obligaban a desafiar la niebla de esas horas. Por mucho tiempo me fué espectáculo diario su figura, y en cierta ocasión, uno de sus mejores amigos, el lamentado Alberto Vélez Calvo, me hizo el favor de presentarme a él. $\mathrm{El}$ señor Suárez no recordaba, iy qué iba a recordarlo!, que siendo presidente de la república y acabando de llegar yo a la capital colombiana, habia ido a visitarlo en compañía del eminente jurista y escritor caucano, doctor Adriano Muñoz, entonces consejero de Estado. Por último, le vi muerto. Aquella faz rubicunda de su edad madura se había convertido en una máscara de cera sobre la cual acababa de imprimir cicatrices profundas la garra de la muerte. Así, transfigurado en un despojo de sólo huesos, sin más ligamento que la piel de asceta, abandonó para siempre sis modesta casa de la Calle Quince, de cuyas vecindades no me he movido, en mucho tiempo. Después fué segado el memorable papayo, y la residencia sufrió fundamentales reformas. Hoy son muy pocos los que, al pasar por alli, saben que en esa casa habitó y escribió Los sucños don Marco Fidel Suárez. 
Pues bien, el público persigue en Suárez al escritor, que era. el aspecto sustantivo de su personalidad. El lo sabía, y acaso por eso mismo consumió sus últimos años sin alzar la cabeza de las cuartillas, en una fiebre de producción que causaba asombro, dada la edad en que realizó la obra magna de Los stieños. Porque Suárez sería, a no dudarlo, una de las grandes figuras de nuestra literatura si sólo hubiese dejado su oración sobre Jesucristo, sus estudios gramaticales, sus páginas sobre Zea, Murillo Toro, Carlos Holguín, Núñez; sus discursos sobre el carácter, sobre la lengua castellana, sobre Cuervo, o alguna de esas páginas políticas, tan finas y agudas, que solía publicar en el Diario Oficial, como su elogio de la paciencia. Con eso bastaría para que su nombre se venerase al lado de los de Cuervo, Caro y Carrasquilla. Pero las luchas políticas, y el interés, muy razonable, de defenderse personalmente y defender la obra de su gobierno, le llevaron a escribir Los sueños. $\mathrm{Y}$ eso arrancó su nombre de la hornacina académica en que había estado hasta entonces, para entregarlo a la popularidad nacional. Naturalmente, esta popularidad, o más bien curiosidad, se limitaba por entonces al fondo politico de tales escritos, donde la gente veía retratados de dos rasgos definitivos a personajes de mucha acción entonces, aludidos en forma incisiva otros, vueltos estupenda caricatura algunos, $y$ no pocos heridos en lo íntimo del alma. Pero aconteció que muchos de esos personajes murieron, o fueron barridos por los sucesos políticos posteriores; otros, caído el gobierno de que eran personajes representativos, entraron en la tiniebla del anonimato, a tiempo que los sucesos mismos se iban enfriando, como la lava, para no dejar más que ese residuo inofensivo de la anécdota, tan parecido al desperdicio geológico de los volcanes. $\mathrm{X}$ entonces comenzó a destacarse el valor literario"e intelectual de la obra del señor Suárez, con independencia de los hechos políticos que inmediatamente la habían generado.

Porque si los doce volúmenes de Los sueños no contuviesen más que las quejas políticas y contumelia literaria; si no fuesen más que un archivo de caricaturas humanas, $y$ un nido de púas verbales, valdrían, a la verdad muy poco, o sólo tendrian interés para los políticos profesionales. Pero en medio de toda esa aspereza sembró el señor Suárez, a manos llenas, mucha doctrina filológica, incontables y preciosas enseñanzas de orden internacional, verdades históricas de ejemplaridad siempre oportuna, rasgos puramente li- 
terarios de inaudita belleza, divagaciones novelescas llenas de gracia y agilidad, digresiones filosóficas de todo orden, frutos de la propia experiencia, de la lectura de los libros, del trato con los hombres; en fin, hizo como el agricultor que, en campo lleno de guijarros y de trozos de vidrio, arroja toda clase de semillas y de pronto ve aparecer las más variadas y peregrinas especies vegetales, alfombrando aquel áspero e ingrato suelo. Esos son Los sueños del señor Suárez. Esquivada la espina, se encuentra la corola riquísima de pétalos; si se le hurta y si uno se desentiende un poco, poma fragante, madura en suelo clásico, bajo el sol de los siglos; se echa a un lado el pormenor personal, ya sin valor histórico; se obtiene la doctrina segura en muchos órdenes del pensamiento; y si uno se desentiende un poco del hombre justamente rencoroso y justicieramente agresivo, se las halla con el gran escritor castellano, que recuerda por igual a Cervantes y a Santa Teresa, pues poseyendo la infinita gracia del uno, no desdeña la inverosímil naturalidad de la otra.

Lo que constituye un problema al estudiar al señor Suárez es la imposible compaginación de su carácter y de su estilo. El hombre era una cosa; el escritor, otra perfectamente distinta. No había en él, como en Cervantes, esa perfecta unidad entre el temperamento y la pluma. Cervantes, a pesar de lo azaroso y mezquino de su existencia, conservó siempre inalterable el buen humor, e hizo de las miserias cotidianas pajaritas de papel que se levantaban al soplo de la desgracia. Lo que hay de inmortal en Cervantes es esa divina ecuanimidad ante la vida $\mathrm{y}$ ante los hombres, ecuanimidad que apenas se desvía un poco en el sentido de la ironía y de la sátira. Suárez, muy sensible ante la vida a causa de sus precarias condiciones de linaje, y elevado a puesto de máximo honor, fué siempre un resentido en toda la amplitud del término, y trocó en amargura y humorismo los zumos vitales que, en Cervantes, son como la espuma, ligeramente amarga, de una sonrisa desengañada, pero no rencorosa. Mas todo esto es anécdota, e irá quedando en la sombra a medida que la memoria de Suárez entre en esa zona alta del tiempo a donde no llegan los soplos de la tierra sino el aura apacible de las regiones inmortales.

Fuerza es convenir en que Suárez se salvó sólo por la gracia maravillosa de su estilo. Me parece que fué hombre de escaso cau- 
dal de ideas, o que comparado con algunos de sus contemporáneos, como Caro, se echa de ver la parquedad de su acervo ideológico. Claro es que no me refiero a la abundancia de ciertos conocimientos como los históricos y gramaticales, que al fin y al cabo son obra de erudición, y que en Suárez aparecen abundantisimos, perfectamente asimilados, $y$ en ocasiones reforzados con consideraciones originales de mucho alcance. Me refiero a ese poder creador, independiente de la erudición o de los conocimientos científicos, que tienen. ciertas inteligencias dotadas de gran capacidad filosófica, y que las habilita para las vastas abstracciones, para los más complejos procesos inductivos, o para encontrar fácilmente la relación de unas ideas con otras, o remontarse con rápido vuelo a las causas y origenes de las cosas. Es lo que se advierte en Caro, por ejemplo, en cuyos escritos hay siempre más cabida para la especulación original que para la divulgación erudita. $Y$ es que, a lo que se me alcan$z a, y$ dicho sea con toda la timidez del caso, me parece que el talento filosófico fué una de las facultades más endebles en el señor Suárez, al contrario de lo que acontecía con el traductor de Virgilio. En cambio, tuvo el clásico de Los sueños muy desarrollado, lo que podríamos llamar talento histórico, consistente en una genial capacidad para juzgar los hechos humanos, sacar de ellos consecuencias y deducciones de aplicación inmediata, valorarlos a la luz de la moral o de la religión y convertirlos en cosa viva, en entraña misma de la historia. Pero en el terreno de las ideas puras, en el campo de la abstracción especulativa, era el señor Suárez bien endeble. Su misma oración sobre Jesucristo, consumada desde ef punto de vista literario, perfecta en cuanto a corrección literaria, admirable como -creación de estilo, es débil desde el punto de vista de la crítica filosófica, religiosa, o, por lo menos, no va más allá de lo que puede leerse en cualquier buen expositor católico de la vida de Cristo. Pero, cuánta ternura, cuánta delicadeza, cuánta poesía en esa página incomparable... Hay alli párrafos que parecen propiamente de Fray Luis de León. Mejor diríamos, una poesía del cantor agustino, diluida en la más pulcra y armoniosa de las prosas. Valga en este ejemplo:

El caminante que anda por las sendas de nuestras montañas, madruga a veces en medio de espléndida noche, $y$ al levantar los ojos, siente ante su nada $y$ ante la inmensidad de los cielos $y$ ante los arcanos del tiempo, melancólicas fruiciones en que se mez- 
clan el silencio que suena en sus oídos, y los destellos de aquellos piélagos de lumbre. Entonces si de aquella contemplación lo sacan el orto y el ascenso de la refulgente estrella del Pastor, puede recordar a Cristo, que también supera en luz a todo el universo de los seres y que dijo de si: "Yo soy la raiz $y$ el linaje de David. Yo soy la estrella resplandeciente de la mañana".

¿Quién no percibe aquí un eco clarísimo de la "Noche serena" de Fray Luis de León?

Respecto: de ciertos secretos del estilo del señor Suárez, oigamos lo que dice un crítico tan autorizado como monseñor Carrasquilla :

En un articulejo sobre prosodia castellana, que publiqué bace años, escribí lo siguiente: En el incomparable discurso sobre Jesucristo, dice don Marco Fidel Suảrez, hablando de San Francisco Javier: - Mucho tiempo después, al pasar los marinos de Inglaterra frente al promontorio donde murió aquél héroe, detenían sus navíos, y hacían resonar las soledades del mar de la India, saladando a Javier con los honores de almirante-. Digase "muchos años después", "por la isla donde murio"." "saludando al misionero con los honores navales", y el magnífico periodo habra perdido mucho de su grandiosa sonoridad. $Y$ si mudamos la frase "detenian sus navíos", cuya suzvidad contrasta con lo anterior $y$ lo siguiente, diciendo, verbigracia, "paraban sus naves", le babremos quitado el primor exquisito al pasaje.

Ante todo, se ha dicho que el señor Suárez fué un clásico. El público otorga este título a quienes escriben en forma magistral, y eso está bien. Pero yo me pregunto si el concepto de clásico puede extenderse universalmente a todos los grandes escritores del mundo, dentro de cierta unidad de caracteres, o si, por el contrario, cada pueblo imprime un sello especial a la idea de lo clásico, o cada siglo posee un clasicismo distinto. Yo sé que son igualmente clásicos Cervantes, en España; Shakespeare en Inglaterra; Racine en Francia, y Dante en Italia; pero, icuánta diferencia entre estos genios! ¿Qué es lo que tienen los cuatro de clásicos? ¿Bajo qué concepto aparecen unidos caracteres mentales tan opuestos? ¿Será simplemente porque cada uno de ellos ocupa el sitio más alto, como escritor, dentro de su respectiva nación? ¿O será porque el mérito de los cuatro puede reducirse a un común denominador? ¿ $\mathrm{Y}$ cuál seria este denominador? ¿Su estilo? Jamás. ¿Su concepto estético 
del arte? Tampoco. ¿Su filosofía de la vida? Mucho menos. ¿Entonces qué? Necesariamente tenemos que buscar algo que los uniforme, y ello tiene que ser, fuera de su indiscutible excelencia como escritores, el hecho de haber sido los cuatro profundos exploradores de la naturaleza humana, de haber enriquecido el mundo del espiritu con sorprendentes hallazgos sociológicos, de haber puesto de manifiesto un rasgo poderoso del alma, un aspecto desconocido de la vida, en fin, de haber creado a la manera divina, es decir, dando vida a seres, ideas o afectos hasta entonces desconocidos o poco estudiados. Por eso son clásicos. Pero hay otra manera de serlo, más propia de los hombres de ingenio o de talento, ya que aquella es exclusión de los genios, y consiste'en el buen uso del idioma, de manera que escriban como lo hicieron los príncipes del lenguaje, con estilo que sea ejemplar, vale decir, que sirvà a su vez de modelo a otros escritores. Así es clásico, a lo que yo presumo, el señor Suárez.

Pero surge aqui otro escollo. El clasicismo, ¿es la imitación de los grandes modelos, o qué clase de imitación debe ser aquélla? Unos imitan a los clásicos tomando de ellos, literalmente, giros y modos de decir, palabras y construcciones que fueron valederas en su época, pero que trasladadas a una distinta suenan mal. Pongo, como ejemplo de este clasicismo, a doñ Juan Montalvo, advirtiendo que en Montalvo esta imitación es genial, y que, en ocasiones, no parece tal imitación, sino modo propio y original de escribir. Otros no llegan a la maestria del ecuatoriano, y dejan ver demasiado la trama burda del calco, apareciendo como afectados, arcaicos y arqueológicos. A ninguna de estas especies pertenece el señor Suárez. Su estilo es lo menos. Montalvo que pueda darse, y lo más distante de la copia presumida con apariencias de clásica. Su prosa, por el contrario, no recuerda visiblemente a la de ningún escritor castellano del Siglo de Oro, aunque se parezca a todas ellas. Entonces, ¿ cómo es clásico el señor Suárez?

Pues como debe serlo todo grande escritor. Tomando de los grandes maestros del idioma su lección perdurable de buen gusto, de claridad, de proporción, de orden y armonía del estilo, de pureza: gramatical, de elegancia expresiva, y fundiendo todos esos elementos, de orden más o menos técnico, bajo el soplo de eso que se llama la gracia, virtud de esencia inexplicable, pero que suele dar 
a toda obra creada por el hombre un cierto aire de cosa espontánea, suelta y juvenil, como debida exclusivamente a la sabiduria de la naturaleza. Así procede el señor Suárez, y de allí que su estilo parezca cosa de su invención, por más que, en algunos momentos, nos recuerde a éste o a ese escritor, lo que es inevitable, aun entre los genios, pues el pensamiento y el lenguaje son obra solidaria de la cultura.

Tenemos, pues, que Suárez fué un clásico, pero un clásico colombiano, $o$, si se quiere, americano, puesto que necesariamente tuvo que infundirle a su estilo el aliento de su nación, de su raza, de su tiempo, como har hecho todos los escritores de nota en sus respectivas épocas. Porque ser clásico es, entre otras cosas igualmente razonables, pertenecer a su tiempo, pero profundamente, hasta compenetrarse y confundirse con él. Cervantes es toda la España clásica, así como Dante es toda la Edad Media. El señor Suárez fué el colombiano más representativo de su tiempo, por su educación humanística, por su sabiduria gramatical, por la entereza moral de su conciencia y hasta por sus costumbres personales. Razón de más para que merezca, también por estos títulos, el dictado de clásico. Pero, fuera de su íntimo parentesco con su pueblo y con su siglo, tuvo el señor Suárez otra virtud necesaria al escritor de verdad, y fué una cierta vibración particular de su estilo, que no se confunde con el acento de ningún otro escritor nacional, aun cuando se asemeja a todos ellos en los caracteres generales de corrección, claridad y elegancia. Igualmente claros, correctos y ele-. gantes son Santa Teresa, Fray Luis de León y Cervantes; pero ninguna persona medianamente culta podría confundir, ni en suenos, sus respectivos estilos. ¿Con cuál pudiera confundirse el de don Marco Fidel Suárez? Creo que con ninguno, en Colombia. Cuervo es igualmente correcto y elegante; pero le falta la enorme gracia que asistió al señor Suárez. Caro tiene mucho más vigor, y un aliento imaginativo poderosísimo que faltó en buen grado al escritor de Los sueños; pero éste me parece más flúido y espontáneo que el formidable humanista. Rafael Maria Carrasquilla es muy atildado y claro, pero carece de fervor lírico; Suárez, en cambio, se eleva frecuentemente a regiones poéticas, y mata toda retórica en fuerza de su sinceridad y pasión. De manera que el estilo de don Marco Fidel es inconfundible aun cuando, por otra parte, sea cosa difícil decir en qué se diferencia exactamente de los demás. Pro- 
pongamos, no obstante, esa cuestión. ¿En qué se diferencia el estilo del señor Suárez, del estilo de los otros escritores colombianos, entendiéndose que se trata sólo de aquellos que puedan hombrearse con el autor de Los sueños? A mi entender, en varios y contradictorios caracteres. Aclaro, una vez más, que no me refiero a las condiciones de corrección gramatical, de propiedad idiomática, pues en esto todos los buenos escritores se parecen, desde luego que son unas mismas las doctrinas científicas que acatan para la materia. Pero en cuanto a las condiciones estéticas del estilo, ya la cuestión es diferente, pues aqui prevalece un elemento personal por encima de los cánones impuestos. El estilo del señor Suárez es la llaneza misma, junto con la gracia más ágil que pueda imaginarse, y sin que esto le impida elevarse en ocasiones a cumbres airosas del pensamiento, o alcanzar momentos de intensidad expresiva sorprendente.

Esto de la llaneza es aparentemente simple, pero muy complicado en el fondo. La llaneza no es la simplicidad, ni el sentido elemental de la frase, ni el lugar común, ni el ponerse al alcance del vulgo por lo trivial de las ideas o del lenguaje. Es todo lo contrario. La llaneza, en el orden literario, equivale a la bondad en el campo de la moral. No son buenos ni el rústico ni el tonto, por más que lo parezcan, sino el hombre de recias disciplinas, que ha vencido completamente al hombre viejo, de que habla San Pablo, y se ha revestido del Cristo. A la verdadera bondad sólo se llega después de muchos sacrificios, sobre todo del sacrificio del egoísmo. Comprendo que hay gentes naturalmente buenas, pero el término suele tomarse entonces en sentido social; penetrando en el fondo de aquellas conciencias, suelen hallarse monstruosas aberraciones. También acontece que existen escritores naturalmente llinos, pero éstos son generalmente los ignorantes, los hombres de escasa cultura, los "primarios" irresponsables. Pero la otra llaneza, la de Suárez, es fruto complicado de mucho estudio, de mucha disciplina, de mucha reflexión, y a ello sólo se llega después de haber limpiado el pensamiento de excesos y redundancias, y de haber luchado con el lenguaje para extraer de él únicamente las fórmulas de mayor poder expresivo. Así se llega a la consumada llaneza del señor Suárez.

Pero la llaneza necesita un complemento indispensable para no degenerar en la simple salmodia discursiva, o en el canto llano gramatical. Es la gracia. La gracia imprime movimiento a la naturali- 
dad, y hace profundamente expresiva la sencillez. Es la sal que se le vierte al candor para quitarle su inevitable aire de tontería. Si el estilo del señor Suárez no poseyera este condimento espiritual, sería insípido. La gracia es su razón estética de ser. No sólo aquella que se traduce en gracejo, chiste o ironía, como pudiera pensarse a primera vista, sino aquella otra que depende del giro mismo del pensamiento, o del modo especial de considerar las cosas. Por esa razón el estilo del señor Suárez no deja sensación de cosa herrumbrosa, sino de materia pulimentada y brillante. Siempre es nuevo, como la verdad y como la vida. Se le lee hoy como se le leyó ayer, con idéntico deleite. Puede ser que algunas de sus ideas no llamen ya la atención, o que no pocas de sus apreciaciones aparezcan como. trasnochadas; pero de lo que si hay seguridad completa es de que el giro artístico en que vertió esos pensamientos conservará siempre su vitalidad literaria, exactamente como acontece con algunas. danzas, orientales o paganas, que no obstante haber perdido por completo su significación litúrgica, siguen cautivando la imaginación nada más que por la expresión rítmica de los movimientos.

Lo que no le impide al señor Suárez elevarse, en ocasiones, a esferas de sublime contemplación; pero aun en este caso, su estilo. permanece idéntico a sí mismo, sin encrespamientos ni raudos despliegues verbales. Es llano en la esfera de lo habitual, como lo es: en las altas zonas de lo sublime, sin degenerar nunca en el énfasis retórico. Acontece, por el contrario, que un artista muy consciente de su técnica, como lo fué el señor Suárez, suele extremar la sencillez en los momentos más patéticos de la emoción, para que ésta aparezca desnuda, sin el auxilio de la hinchazón oratoria a que suelen apelar otros escritores para dar la sensación del arrebato o del-arranque lírico. El señor Suárez no procede nunca de esa manera. A medida que se inspira, su lenguaje, como el aire de las alturas, se enrarece, es decir, va perđiendo densidad idiomática, hasta. convertirse en una especie de exhalación interior. En otras ocasiones, a la inversa, recarga el escritor intencionalmente el senticla. de las frases, agrupa elementos, sobrepone giros, 'con el objeto de lograr un efecto expresivo de máxima intensidad. Pero siempre sin mengua de eso que hemos considerado como la cualidad esencial de su estilo: la llaneza. A este último se acoge cuando necesita dejar bien grabada en el ánimo de los lectores una circunstancia par- 
ticular, ya se trate de una sentencia, de una caricatura verbal, o de un paisaje. Cito este maravilloso párrafo del "Sueño de Blas Gil y el Moro", que dice:

La tarde del 3 de enero de 1901 fué una de las más despejadas que se ven en la provincia del Tequendama, región que corte desde la encumbrada cornisa en que descansa la Sabana de Bogotá, por una de cuyas abras da el río Funza el salto audaz que es maravilla del globo, hasta donde el Magdalena lame las tierras ardientes de sus vogas. Bella fué esa tarde, tendida como palio de luz y de zafiro sobre pliegues de vegetación, en que se dilataba la vista, pasando de las sombras de las cañadas a las cumbres iluminadas de los montes, del v́erde amarillo de los cañadulzales al verdinegro de los plantios de café; del pajizo de los potteros y del color franco de la vegetación más cercana, al azul vaporoso de las cordilleras más distantes. Cerraba este cuadro por el oeste de la cordillera del Quindío, confundiendo sus cumbres con los campos del cielo, o velandolas con los vapores del Tolima y del Santa Isabel, o dejando ver más allá de sus perfiles nubes guarnecidas de fuego, oro, y rosa, flotantes sobre los valles del Cauca. Al caer de aquella tarde, y al compás de ella entraba en el ocaso, iba la noche subiendo por el oriente, y ostentando sobre sus crespones el diamante solitario de la estrella Siris, y las siete luces de Oriơn, de aquel Orión que es la joya más espléndida con que se adorna la hija del Caos, madre del Sueño y del Olvido. Podía, pues, decirse, que en esta tarde del 3 de enero de 1901, habían entrado en competencia los horizontes de los Andes y los de Urano a conmover a los espectadores con las aspiraciones y recuerdos que se sienten delante de las lejanias de la tierra o de las profundidades estrelladas de los cielos.

Esto es sublime, y para aquilatar la perfecta belleza de semejante descripción, basta leer, en el capítulo VII de La perfecta casada, de Fray Luis de León, una pintura del amanecer que hay alli, para que después se diga qué es preferible: si este crepúsculo del señor Suárez, o la aurora del incomparable agustino. Creo que el lector permanecerá indeciso, como los poetas o como los pintores, entre la grandeza de dos crepúsculos igualmente arrobadores y espléndidos.

Perteneció el señor Suárez a una especie de hombres cuyo tipo tiende a desaparecer en el pais. Este tipo fué el de sujetos a quienes importaba, sobre todo, poseer una filosofía y un credo religioso, antes que conocimientos de otra índole. Necesitaban ellos estructurarse mental y moralmente para entrar en los dominios de la 
ciencia, de la política o de la literatura. De allí que esa generación hubiese poseido hombres de una sola pieza, tanto en sus convicciones políticas como en sus predilecciones literarias. No estaban a merced de las novedades, ni del éxito del momento, sino que fortalecidos en su convicción, que para ellos representaba frecuentemente la filosofía de su propia existencia, juzgaban las cosas en ocasiones dogmáticamente, pero con absoluta sinceridad e ilustrándolas con toda clase de argumentaciones válidas. Podemos no estar de acuerdo con algunos asertos literarios de Caro, por ejemplo, pero no por eso se dejan de leer con sumo agrado y con sumo provecho los escritos en que sostiene puntos de vista que no pueden ser los nuestros. Pues otro tanto acontece con el señor Suárez. Se discrepa de él en ocasiones, pero se admira el caudal de erudición y de ciencia con que sostiene sus tesis. No sucede lo mismo con hombres que suelen mirar las cosas desde puntos de vista relativos y que, por consiguiente, no se creen obligados a ilustrar y fundamentar sus creencias. ¿Para qué acopiar pruebas, y acudir a los vastos campos de la erudición histórica o filosófica, si lo que hoy se afirma mañana puede ser negado, y si un capricho de la persona o un ligero cambio de los acontecimientos pueden desviar completamente el juicio por cauces nuevos e inesperados? A la verdad, es esto lo que se advierte en conciencias y criterios desprovistos de esa formación filosófica y moral que produce las grandes e incontrastables convicciones. En el señor Suárez se advierte lo contrario. Como crítico literario, sus ideas descansan en sus profundas convicciones de humanista y de clásico, y cuando puede aplicarlas en toda su extensión a un escritor que las representa auténticamente, realiza estudios tan magistrales como sus estudios sobre Núñez y Holguín, sobre Juan de Corral o Francisco Antonio Zea. Como político, sostiene la absoluta dependencia que esta ciencia debe tener en la ética cristiana, y redacta los admirables documentos que, bien como jefe de un partido político, y como presidente de la república, o como simple ciudadano encargado de vindicar el buen nombre de su administración, escribe a diario, con pluma en que a la claridad de Balmes se juntan la sabiduria política de un Saavedra Fajardo o de un Donoso Cortés, y en ocasiones el esguince mordaz de un Quevedo. Hay además, la circunstancia de que en el señor Suárez, como en todos los grandes escritores, unas facultades les prestan ayuda a las otras, y los recursos de una ciencia se ponen al servicio de 
otra cualquiera de las disciplinas de la inteligencia. Lo que el señor Suárez no alcanza a comprender mediante la experiencia personal, lo deduce de los datos de la psicología general y de las enseñanzas de la historia. Por eso acude frecuentemente a los dictámenes de la conciencia o al veredicto de los siglos. El escritor político se siente auxiliado a cada paso por el teólogo y el moralista. Al historiador apoyan el filósofo y el erudito. Al lado del crítico literario se hallan siempre el filólogo, el gramático y el estilista. Para fundamentar las efusiones del místico o del escritor religioso, acuden el teólogo y el exégeta, y-así sucesivamente, de manera que cada página del señor Suárez viene a ser como una sintesis de los más variados y profundos conocimientos.

Pero hubo en el señor Suárez un aspecto dominante de su inteligencia, una actividad casi exclusiva de su conciencia de hombre y de escritor, y fué la literatura religiosa. El señor Suárez es, por definición, un escritor religioso. Urge aquí aclarar un poco este término. No fué propiamente un polemista católico, en el sentido de la controversia, pues casi nunca anduvo enredado en cuestiones de este orden, habiéndose limitado a la exposición de puntos de doctrina o de moral. No tuvo, pues, punto de contacto con los dos mayores controversistas católicos que ha tenido el pais, y que fueron don José Joaquín Ortiz y don José Manuel Groot. Sólo en uno de Los sueños, en el de Renan, se lanza abiertamente a la polémica, y eso contra un enemigo histórico, no real. Ortiz y Groot si fueron hombres de lucha diaria en el estudio de la discusión religiosa. El primero en sus célebres "Cartas de un sacerdote católico", en que se enfrentó a uno de los más aguerridos polígrafos de la época, hombre de acción parlamentaria; de inagotable elocuencia, de vastos $y$ profundos conocimientos jurídicos, además de novelista, poeta y dramaturgo. Me he referido a don José Maria Samper. El otro, mejor equipado que Ortiz en cuanto a conocimientos científicos, y dueño de una de las más grandes erudiciones en materia religiosa que ha conocido el pais, refutó a Renan, y sentó sobre el famoso heresiarca francés principios críticos que después han sido confirmados tunánimemente, aun por los historiadores compatriotas de Renan. El señor Groot calificó al autor de la Vida de Jestís de simple novelista impio, $y$ hoy ni librepensadores de bajo fondo se atreven a citar a Renan como autoridad en asuntos bíblicos. Se le tiene, eso sí, por el más puro de los estilistas franceses. 
El señor Suárez no fué, pues, ni polemista religioso ni controversista católico, quizás por no haber tenido ocasión para ello, ya que los tiempos en que actuó fueron de aceptación plena de los postulados católicos, tanto en la vida privada de los ciudadanos como en la pública de la nación. Hubiera alcanzado tiempo de efectiva persecución religiosa, como los que vieron combatir a los dos próceres antes nombrados, y entonces la Iglesia de Cristo habria tenido en él a un confesor integérrimo, y probablementé a un mártir, pues su fe reclamaba la prueba del hierro y de la afrenta, para salir victoriosa. A falta del sacrificio efectivo de su vida, dedicóse con ardor apostólico a la exposición de doctrinas religiosas, y a la siempre hermosa y oportuna literatura apologética, en la cual dejó páginas que Hernesto Hello hubiera agregado a sus Vidas de Santos.

Su oración sobre Jesucristo es la obra más pulcra que salió de su pluma; pero al lado de ellas hay otras que resisten la comparación con esa deslumbrante pieza literaria. Sólo que permanecen medio olvidadas, pues les ha sucedido lo que al agua que salta entre mármoles, y es que el prodigio de la piedra ornamentada hace olvidar el fresco milagro de los cristales que se rompen con música siempre nueva. Las solemnidades del primer Congreso Eucarístico celebrado en Colombia le han dado a ese discurso un relieve inmortal. Sin embargo, la oración sobre San Francisco de Asís, y la pronunciada en el Colegio de San Bartolomé, con ocasión del Congreso Mariano, merecian también hallarse esculpidas en láminas de oro, y colocadas en el interior de una Basílica. En la primera hay párrafos que podrian ir engastados en la oración sobre Jesucristo. Este, por ejemplo:

Obra como ésta, de tamaño infinito, $y$ de capacidad inmensa, la consumó ya el Señor; pero al mismo tiempo la prosigue por medio de una facultad propia de su omnipotencia y que consiste en it sugcitando sin cesat imitadores suyos. Los humanos se llevan al sepulcro su genio, su esfuerzo y todo lo personal de su existencia; sus proezas se desvanecen así, su gloria se trueca literalmente en puñados de cenizas, y todo su poder viene a caber en una estrecha fosa. A radie sino a la muerte pasa la gloria mundana, aunque ésta trate de sobornar a la memoria para que la proteja; a ninguno sino a los gusanos se transmite el legado de los llama- 
dos inmortales, cuyas obras de inteligencia y de valor se convierten en alimento de aquellas larvas. Pero Dios Hombre sí tiene la virtud de que sus atributos, sus obras, sus milagros, sa evangelio de verdad y de justicia, eso que no se eclipsa, ni se destiñe, ni se desvanece, ni se confedera con la ignorancia y la pasión, sino que forma un patrimpnio inmarcesible en manos de Jesús y en las obras de sus discípulos. Ellos, al cabo de los siglos, hacen resonar el órgano de la redención con voces que nunca se amortiguan, con armonias que jamás se apagan, a los pies de la santidad personificada, $y$ ante los ojos que envuelven en luz el universo.

El otro discurso, que se halla inserto en el llamado "Sueño de Chiquinquirá", el cual figura en el tomo undécino de Los sueños, donde puede verse asimismo el discurso sobre San Francisco de Asís, es una página maestra de la literatura piadosa, como raramente se encuentra en los místicos españoles, a causa de sus condiciones de unción religiosa, ternura humana y fervor místico. En la clásica obra de San Alfonso de Ligorio sobre la Virgen, no hay capítulos que superen al escrito del señor Suárez, ni aun los más fervorosos. Ignoro si el señor Suárez conoció la admirable obra de Grignion de Montfort sobre la devoción mariana, obra de insondable profundidad y de verdadero aliento profético, que es el más grande $y$ hermoso diamante en que pueda posar la planta la corredentora del género humano; pero si el señor Suárez no conoció esa obra, cuya divulgación universal es cosa de nuestros días, sí coincidió con el venerable tratadista en afectos e ideas, en lo concerniente al culto mariano. El discurso del señor Suárez tiene como objeto a la Virgen de Chiquinquirá. Transcribo algunas ideas:

El cuadro no es del pincel de Rafael, ni tecibió la inspiración de Murillo; no cruzó el mar para venir al Nuevo Mundo desde alguna ciudad europea, nodriza de las artes: lo ejecutó un aficionado, cuyo nombre apenas se recuerda, valiéndose de un lienzo tejido por mano indígena, que tal vez temblaría al recuerdo de la reciente conquista; $y$ lo pintó no con artística paleta, sino con tietras del campo, mezcladas con zumo de hierbas y de flores.

Realmente, es imposible transcribir más, pues el discurso tiene tal unidad que darlo en fragmentos sería como rasgar un manto de seda para mostrar la calidad preciosa del tejido. A esa página sólo le falta la rima para que se convierta en uno de los más her- 
mosos poemas escritos en castellano en honor de la Virgen. Sería de desear que se hiciese con ella el trabajo de versificación que realizó Caro en el elogio de la edad de oro, que figura en el Quijote. De este modo se comprobaría, como ya to hizo el gran humanista bogotano respecto de Cervantes, cuántos y muy aprovechables elementos poéticos hay en la prosa del señor Suárez, no sólo en el orden de las ideas e imágenes, sino en el del propio ritmo y número de la prosa, la cual puede transformarse fácilmente en verso, con ligeras alteraciones y cambios convenientes.

Al Congreso nacional fué presentado un proyecto de ley sobre erección de una estatua al señor Suárez. Ignoro qué suerte haya corrido, o corra en los próximos debates. El nombre del señor Suárez es todavía para muchos piedra de contradicción, y en torno suyo no se han acallado los odios ni las enemistades. Probablemente sucederá con este hombre lo que estamos presenciando con Núñez: un debate permanente sobre su obra y su persona. Además, Los sueños, cuya difusión se hace cada día más extensa, serán los mismos encargados de renovar los ataques a la memoria del señor Suárez, puesto que hay en ellos acusaciones y sarcasmos de esos que no pasan, y que cada generación va recogiendo, bien para aplaudirlos o bien para vengarlos en la gloria y en el renombre del autor. Pero sí existe una zona neutral en la que es necesario que se junten amigos $\mathrm{y}$ enemigos, correligionarios $\mathrm{y}$ adversarios políticos, para verificar un gran acto de desagravio al señor Suárez. $\mathrm{Ni}$ en el campo internacional ni en el de la literatura puede tener el señor Suárez opositores, puesto que mirar con desvío la obra realizada por él en esas dos actividades, implicaría casi una traición a la república. El señor Suárez fué internacionalista de larga y segura visión, y la actual política exterior de la nación no es más que un desarrollo de sus doctrinas. Como escritor, colocó en sitio de honor el. nombre de Colombia, enalteció a la América latina y fué un verdadero paladin de la raza y de la lengua: Glorifiquemos, pues, al internacionalista y al escritor clásico, colocando su estatua frente al nuevo palacio de las relaciones exteriores. El señor Suárez fué sin duda una de esas víctimas escogidas por la Providencia para castigar las culpas de tođo un pueblo. Cúpole, en cierto modo, el más glorioso de los sacrificios: aplacar, en su persona, cóleras y castigos de que habrian sido víctimas muchos de sus conciudadanos, a no haber existido el justo que salda siempre las cuentas pendientes 
con Dios y con la historia. Necesario, pues, que el varón escogido para tan dura prueba, escogido precisamente a causa de su inocencia y de sus méritos, según los misteriosos planes de la economía divina, reciba ahora la parte de la gloria terrena que le corresponde, para que acá abajo la historia quede satisfecha, la justicia social reparada, y los partidos políticos exonerados de una culpa que probablemente ha impedido que marchen con más libertad por los mundos del progreso.

RAfaet Maya 
